\title{
An Investigation on the Relationship between Proactive Personality with Networking, Mediated by Job Satisfaction
}

\author{
Mohammad Babamiri', Rashid Heidari Moghadam², Behnam Mohammadi ${ }^{3 *}$, Younes Mohammadi ${ }^{4}$ \\ 1. Research Center for Health Sciences, Department of Ergonomics, School of Public Health, Hamadan University of \\ Medical Sciences, Hamadan, Iran \\ 2. Department of Ergonomics, School of Public Health, Hamadan University of Medical Sciences, Hamadan, Iran \\ 3. MSc in Industrial and Organizational Psychology, Shahid Chamran University, Ahwaz, Iran \\ 4. Modeling of Non-Communicable Diseases Research Center, Hamadan University of Medical Sciences, Hamadan, \\ Iran
}

\section{Article Info \\ Original Article \\ Received: 2017/12/14; \\ Accepted: 2018/02/19; \\ Published Online: 2018/03/15 \\ DOI: $10.30699 /$ jergon.5.3.50}

Use your device to scan and read the article online

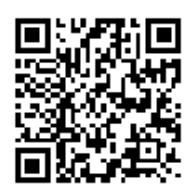

Corresponding Author Behnam Mohammadi MSc in Industrial and Organizational Psychology, Shahid Chamran University, Ahwaz, Iran

Email:

mohammadibehnam19@chmail.ir
ABSTRACT

Background: The purpose of this study was to investigate the relationship between proactive personality with networking by mediating role of job satisfaction. Methods: The research design in this study was a correlation model, through structural equation modeling. The target population in this study was all nurses working in public hospitals in Hamadan that 300 people of them were selected as the sample by simple random sampling. The data collection tools were Proactive Personality Scale (Bateman and Crant), Proactive Behavior Questionnaire (Networking, Ashford and Black) and Job Satisfaction Questionnaire (Brayfield \& Rothe). The proposed model was evaluated using correlation and path analysis method using SPSS18 and AMOS18 software.

Results: Pearson correlation showed that there is a positive and significant relationship between proactive personality with job satisfaction and networking. The path analysis results support the pattern's fit with the data. The findings showed that job satisfaction mediates the relationship between proactive personality and networking.

Conclusion: Job satisfaction strengthens the efforts of proactive person in networking and broadens the career communication network.

Keywords: Proactive Personality, Networking, Job Satisfaction

Copyright $\odot$ (2018, Journal of Ergonomics. This is an open-access article distributed under the terms of the Creative Commons Attribution-noncommercial 4.0 International License which permits copy and redistribute the material just in noncommercial usages, provided the original work is properly cited.

How to Cite This Article:

Babamiri M, Heidari Moghadam R, Mohammadi B, Mohammadi Y. An Investigation on the Relationship between Proactive Personality with Networking, Mediated by Job Satisfaction. J Ergon. $2018 ; 5$ (3) :50-57 


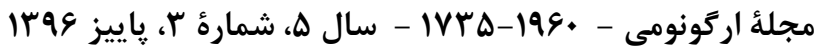

\section{مقالهُ يزوهشى}

رابطُّ شخصيت يويا با إيجاد شبكةُ ر تباطى با ميانجى

محمد باباميرى'، رشيد حيدرى مقدم'ّ، بهنام محمدى "، يونس محمدى

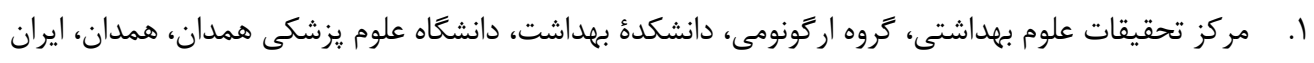

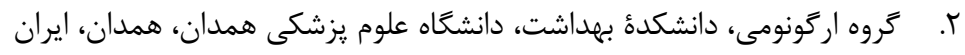

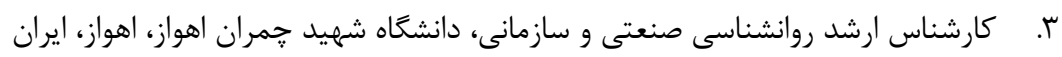

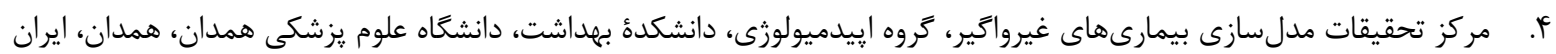

\begin{tabular}{|c|c|}
\hline خلاصه & اطلاعات مقاله \\
\hline 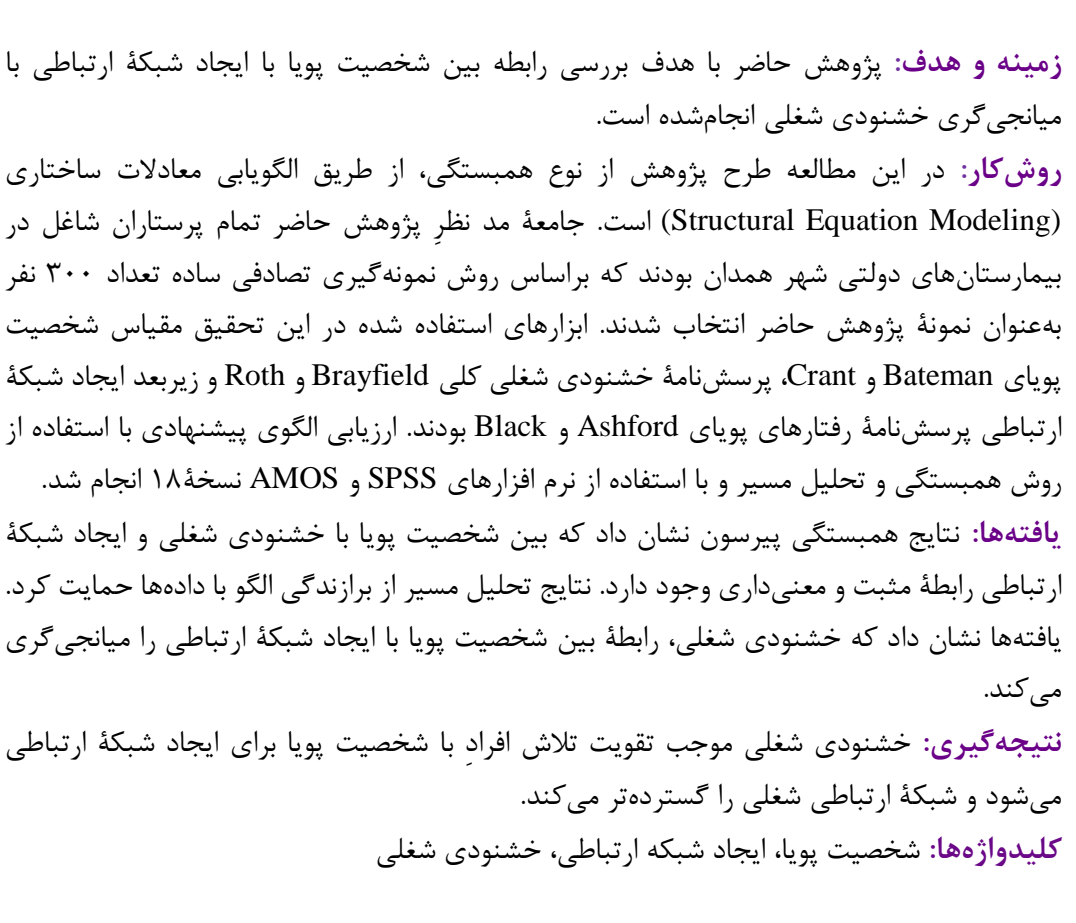 & 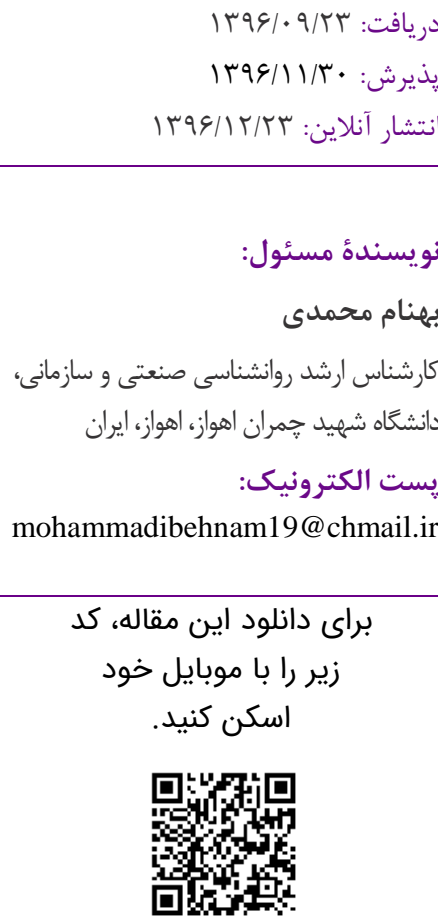 \\
\hline
\end{tabular}

مقدمه

باعث افزايش جشمخير عملكرد سازمان، نشاط روحى

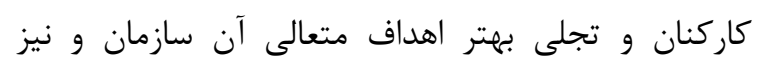
دستيابى به اهداف فردى خواهد شد. در جهان بهان رقابتى امروز، قاعدء رقابت و امنيت شغلى جيزى بيش از خيال يردازى

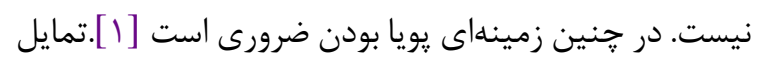
افراد براى كنترل محيط متفاوت است. افراد يويا فعالانه

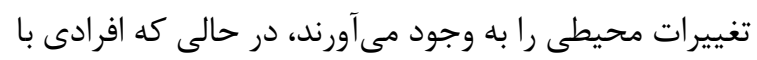

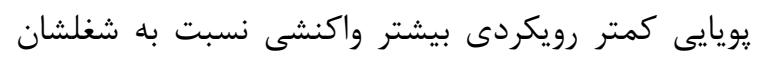

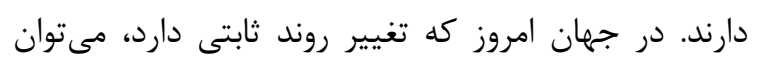
بيش از حد بر اهميت رفتارهاى تويا تأكيد كرد. رفتار يويا
نيروى انسانى كارآمد، شاخص عمدهُ برترى يك سازمان

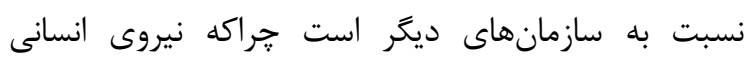
مهرمترين منبع هر سازمان است. كاركنان متخصص، وفادار،

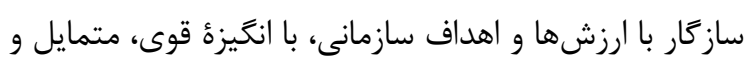

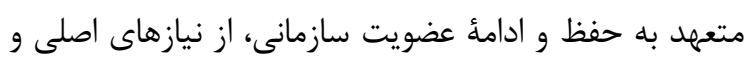
بسيار ضرورى هر سازمان هستند. سازمانها به كاركنانى

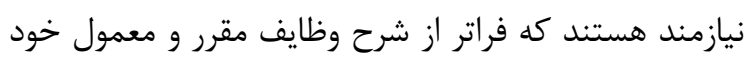

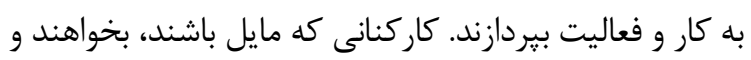

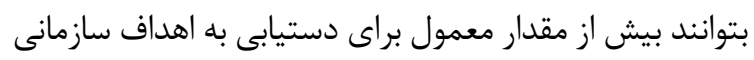

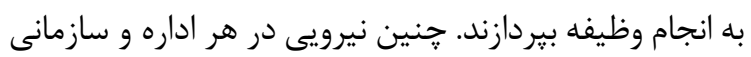


يا سرايدار، كارگر، وكيل، يزشك، فروشنده يا وزير با كسب

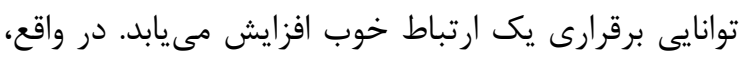

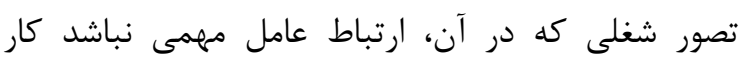
دشوارى است [؟]. يرستارى از مشاغلى است كه فر فرد ساعتهاى زيادى را با افراد گيرنده خدمات مى خَّراند.

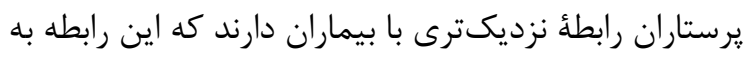

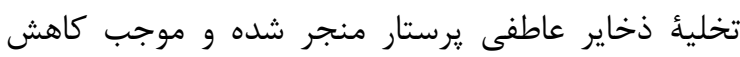

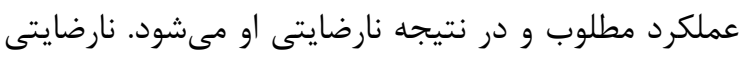

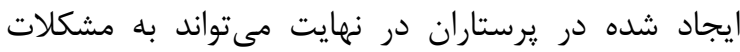

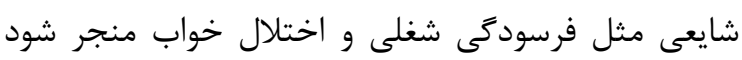

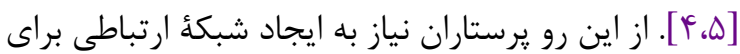

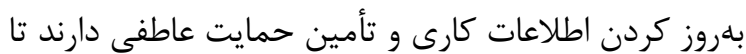
وظيفه خود را به نحو احسن انجام دهند. شخصيت يويا شخصيتى است كه خود را از قيدوبند الجند نيروهاى محيطى رها سازد؛ باعث تغييرات مؤثر شود؛ افراد

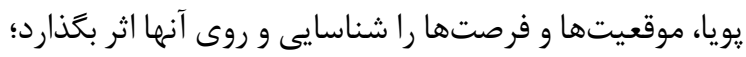

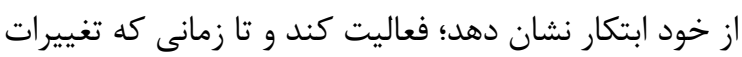

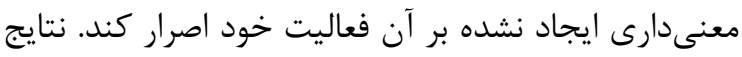

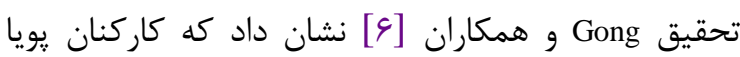

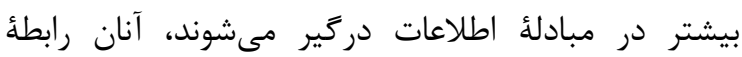
صادقانهاى را ساخته و از آن راه مبادله اطلاعات انجام داند مىدهند، روابط صادقانه موجب خلاقيت مىشود و مبادله

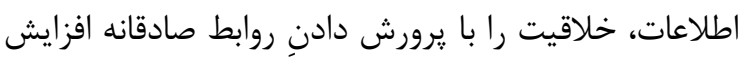

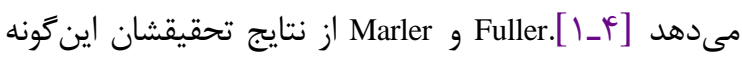
نتيجه كيرى كردند كه افرادى با شخصيت يويا، كرايش به تجربأ موفقيت كار راهؤ بزركترى نسبت به افر ادى با شخصيت بيشتر

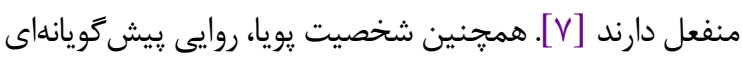

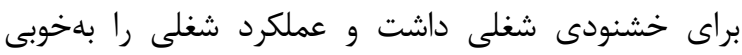

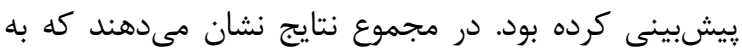

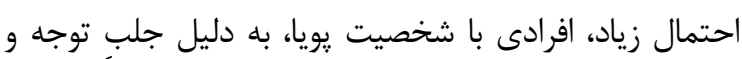
حمايت افراد قدرتمند، در سازمان بيشرفت مى كنند. همجنين شخصيت يويا با رفتارهاى يويايى مثل قبول مسئوليت و اظهار نظر، رابطةٔ مثبتى دارد. خشنودى شغلى نكر شى است كه جَّونكى احساس مردم نسبت به شغل را بهطور كلى يا نسبت به جنبه آناى مختلف

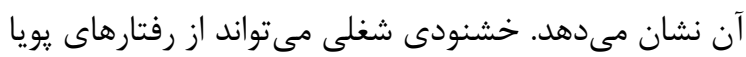

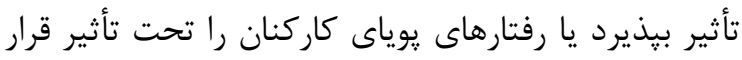
دهد [1]. رفتارهاى يويايى مثل جستجوى بازخورد و ايجاد
در كزينش و فرايندهاى يرداخت مزد در شركتها اهميت

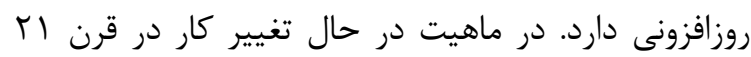

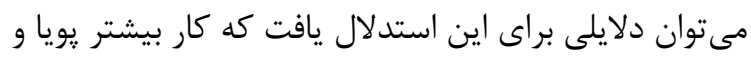

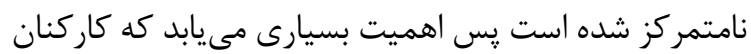
بتواند تغييرات محيط كاريشان را كنترل كنند. برخى افراد آنداد

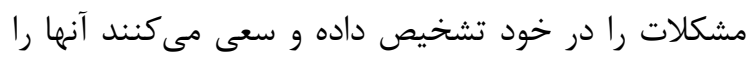

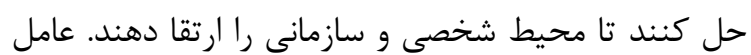

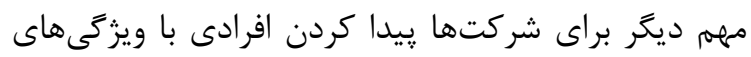

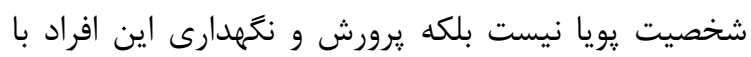

استعداد هم هست [r]. شايد بتوان كفت كه ارتباط، از قديمىترين و در عين حال، عالىترين دستاوردهاى بشر بوده است. ارتباط در

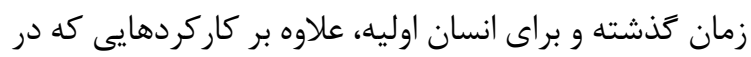
راستاى حفظ حيات و يارى

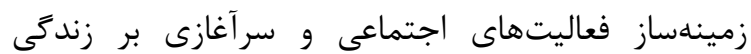

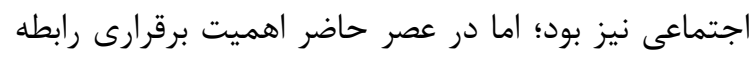

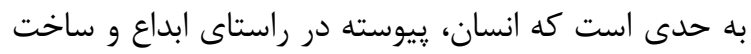

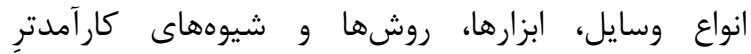

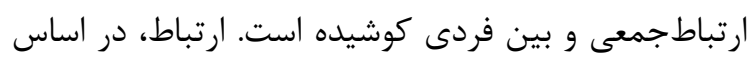

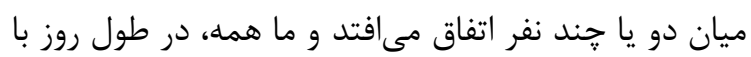
افراد مختلفى ارتباط برقرار مى كنيم. برقرارى ارتباط به ديه دلايل مختلفى مثل كذاشتنِ وقت، بررسى مسائل شغلى و

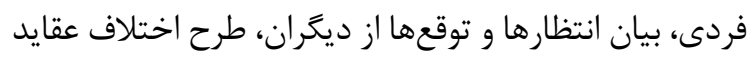

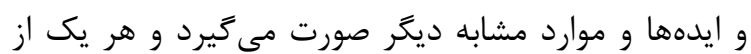
انواع آن در سطوح مختلفى مثل سطح كلامى، سطح

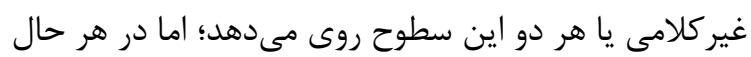

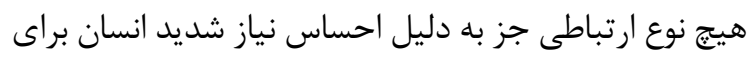
برقرارى تعامل اجتماعى به وقوع نمى ييوندد. با وجود آنكه

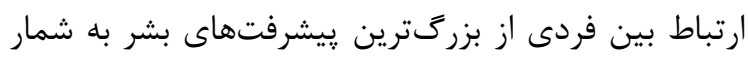

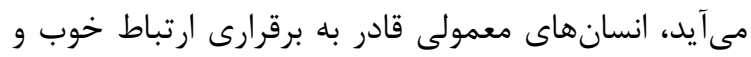

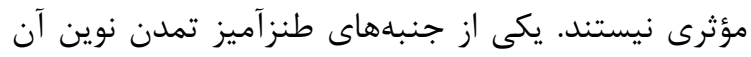

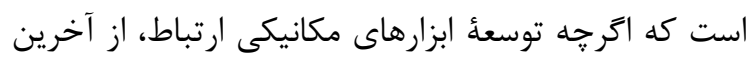

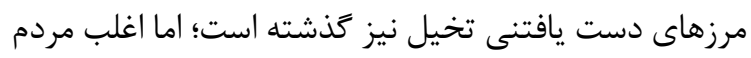

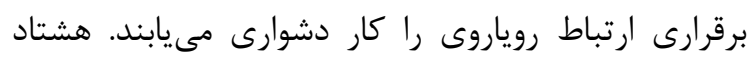

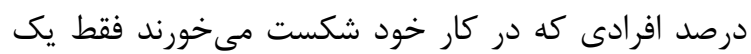

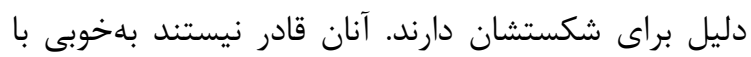

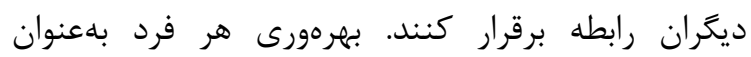

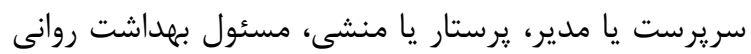


مدنظر به روش نمونه كيرى تصادفي ساده تعداد نمونههاى

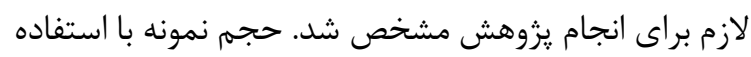

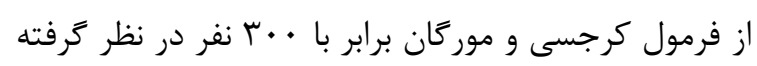

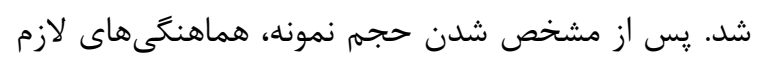

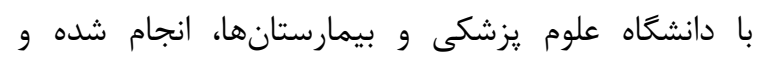

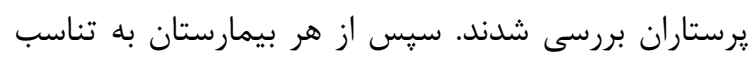

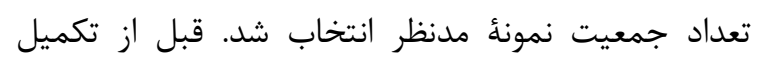

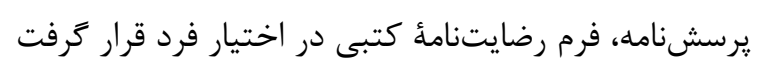

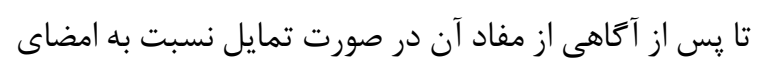

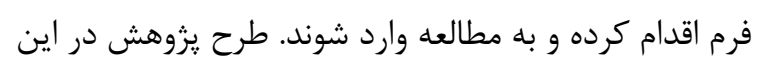

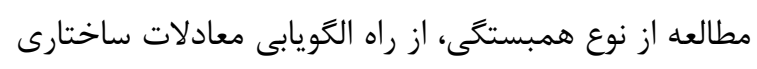
(Structural Equation Modeling) مشخصات آزمودنىها و براى انجام تحليلهاى مقدماتى از

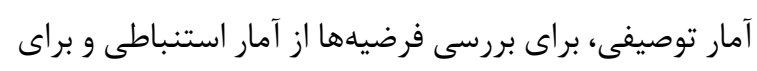

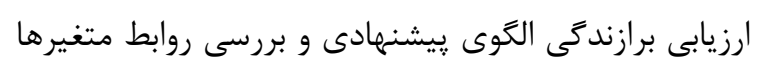

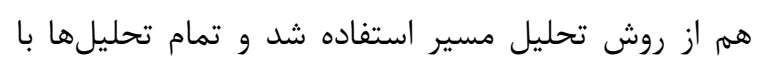

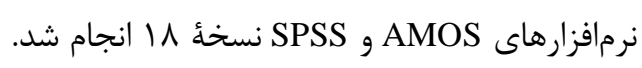

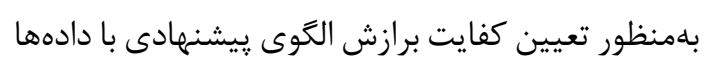

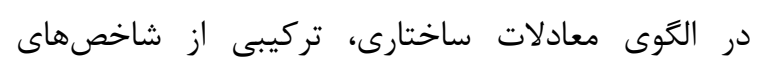

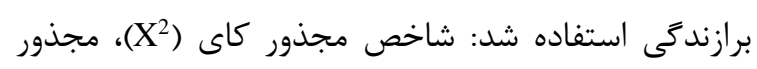
كاى نسبى (

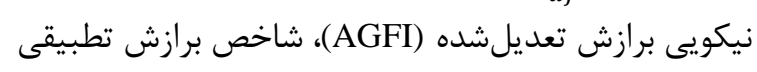

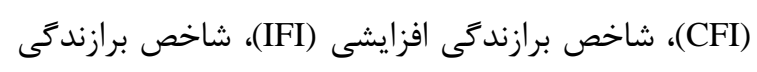

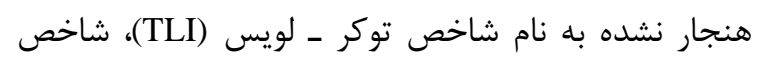

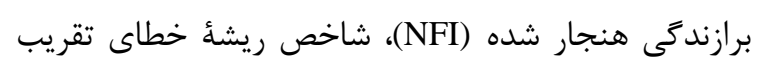

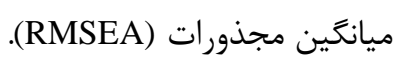

\section{مقياس شخصيت يويا}

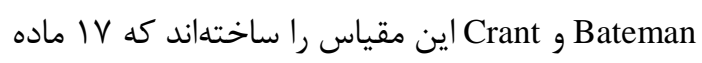
دارد [• [1]. نمرات اين آيتمها براى دستيابى به نمرؤ واحد

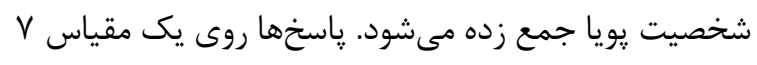

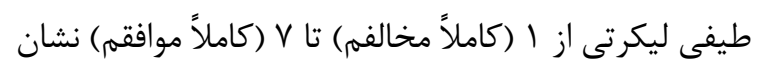

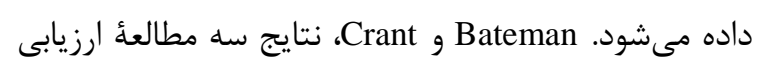

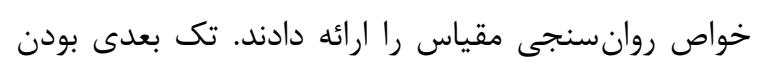

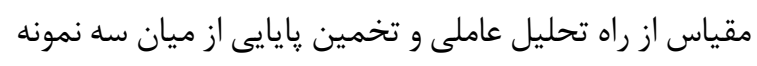

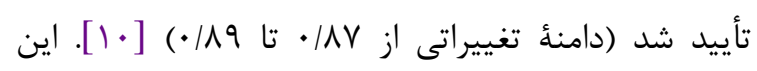

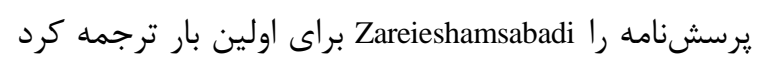
[IT] كه روى نمونهاى •له نفرى از كاركنان دانشخاه علوم

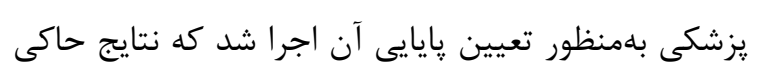

رابطه با همكاران بر خشنودى شغلى تأثير تذار بوده و از آن

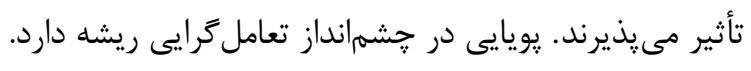

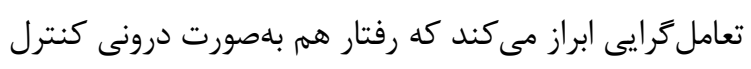

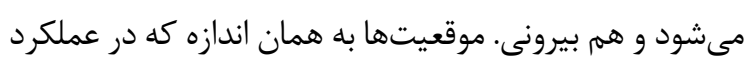

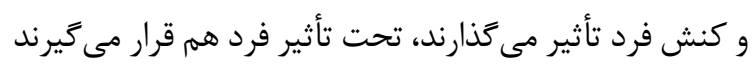

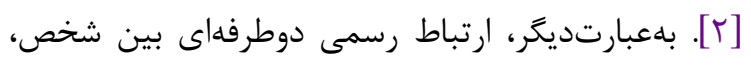

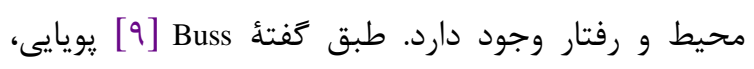

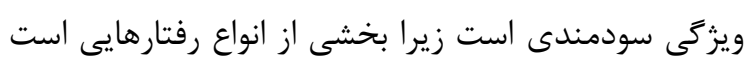

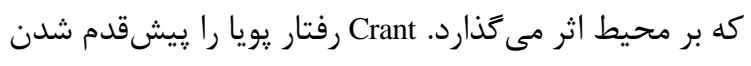
براى بهبود شرايط فعلى يا خلق فرداى جديد تعريف كرده ئرد

است [ب].

فرضيههاى يزوهش حاضر عبارتاند از:

ا. شخصيت يويا بلهور مستقيم خشنودى شغلى راضى را تحت

$$
\text { تأثير قرار مىدهد. }
$$

ك. شخصيت يويا بهطور مستقيم ايجاد شبكةٔ ارتباطى را

$$
\text { تحت تأثير قرار مى دهد. }
$$

r. خشنودى شغلى بلهطور مستقيم ايجاد شبكأ ارتباطى دمد

$$
\text { را تحت تأثير قرار مى دهد. }
$$

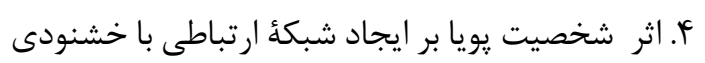
شغلى ميانجى گرى مىشود.

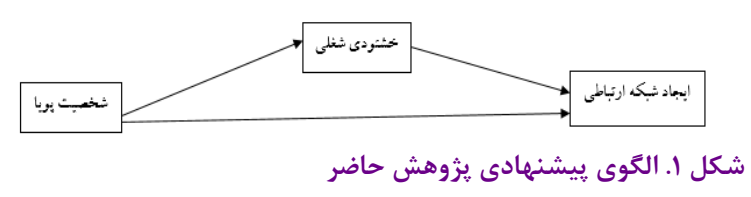

همانَونه كه در شكل 1 مشاهده مىشود الكوى بيشنهادى يزوهش حاضر روابط بين متغيرها را نشان

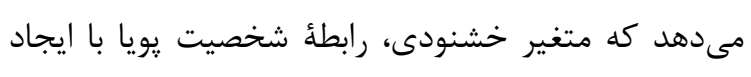

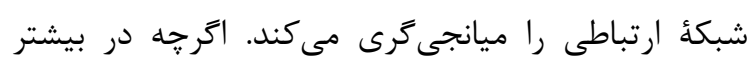

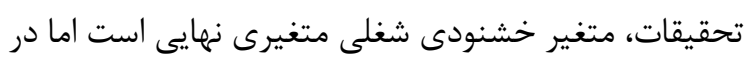

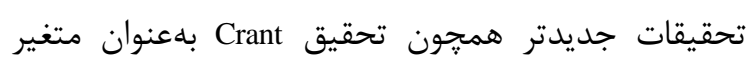

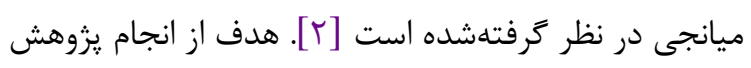

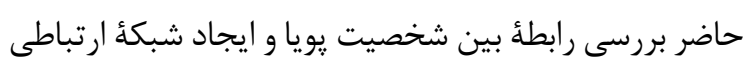

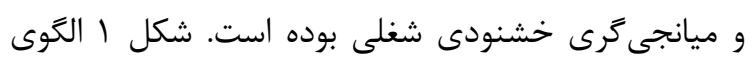
ييشنهادى يُوهش حاضر را نشان مى دهد.

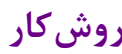

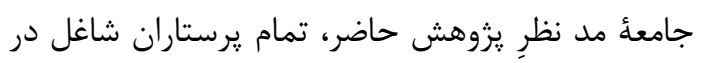

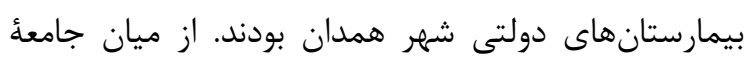




\section{يرسشنامه خشنودى شغلى}

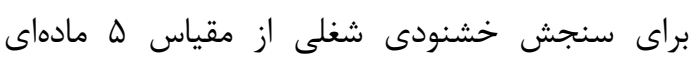

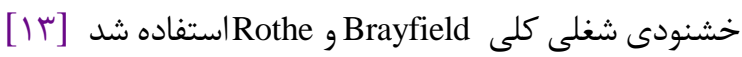

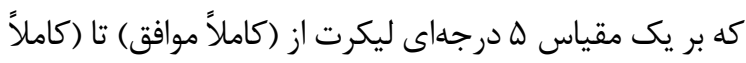

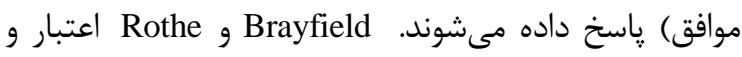

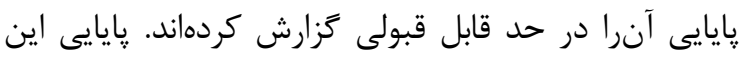

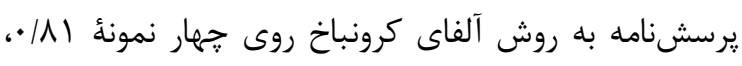

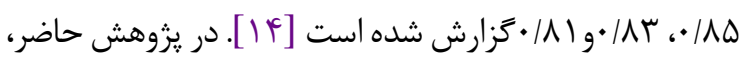

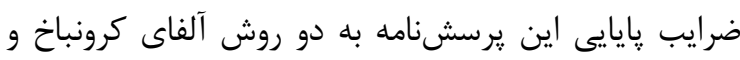

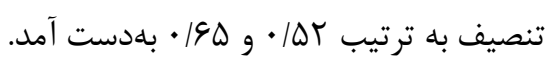

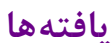

يافتههاى توصيفى مربوط به ميانكَين و انحراف معيار افراد

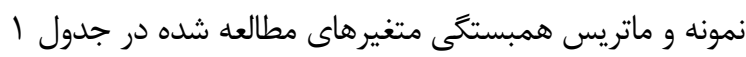
نشان داده شدهاند.

مندرجات جدول ا نشان مىدهد كه اكثر روابط در سطوح

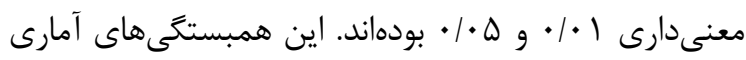

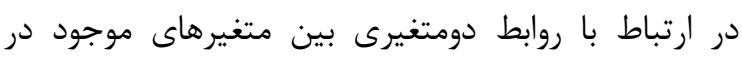
يزوهش، بينش كلى را فراهم مى كنند.
از يايايى مطلوب يرسشنامه بود و با حذف يكى از آيتمهاى

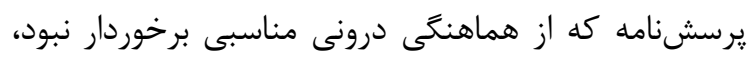

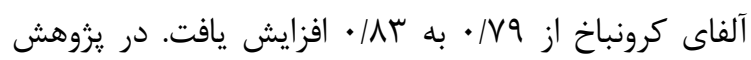

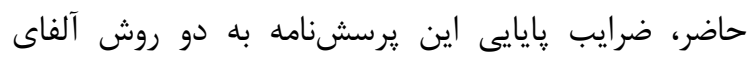

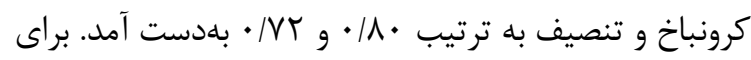
تعيين روايى اين برسشنامه از تحليل عوامل تأييدى استفاده شد كه روايى مطلوبى داشت.

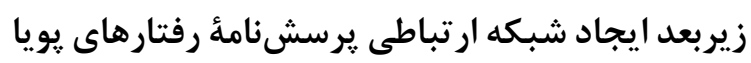

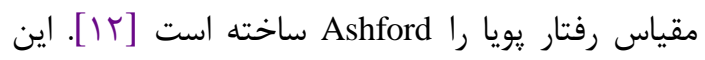

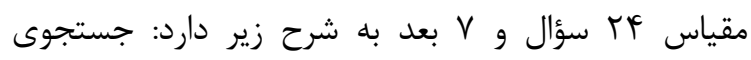

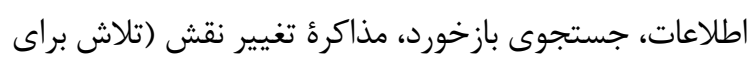

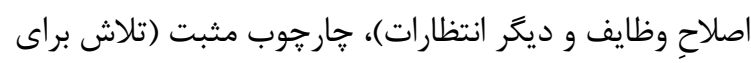

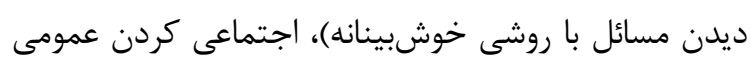

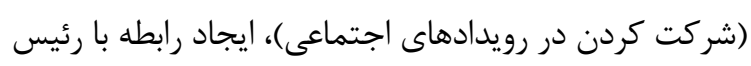

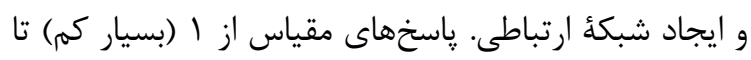

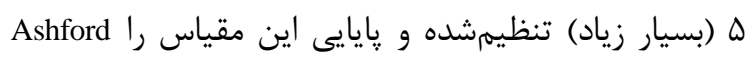

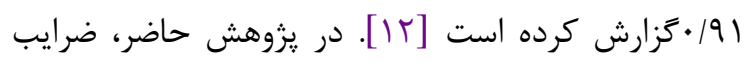

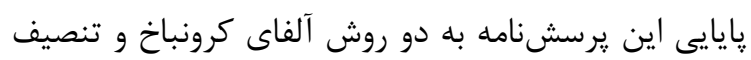

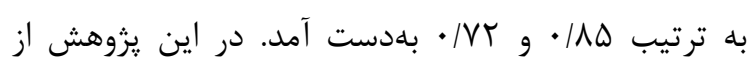
زيربعد ايجاد شبكة ارتباطى استفاده شده است.

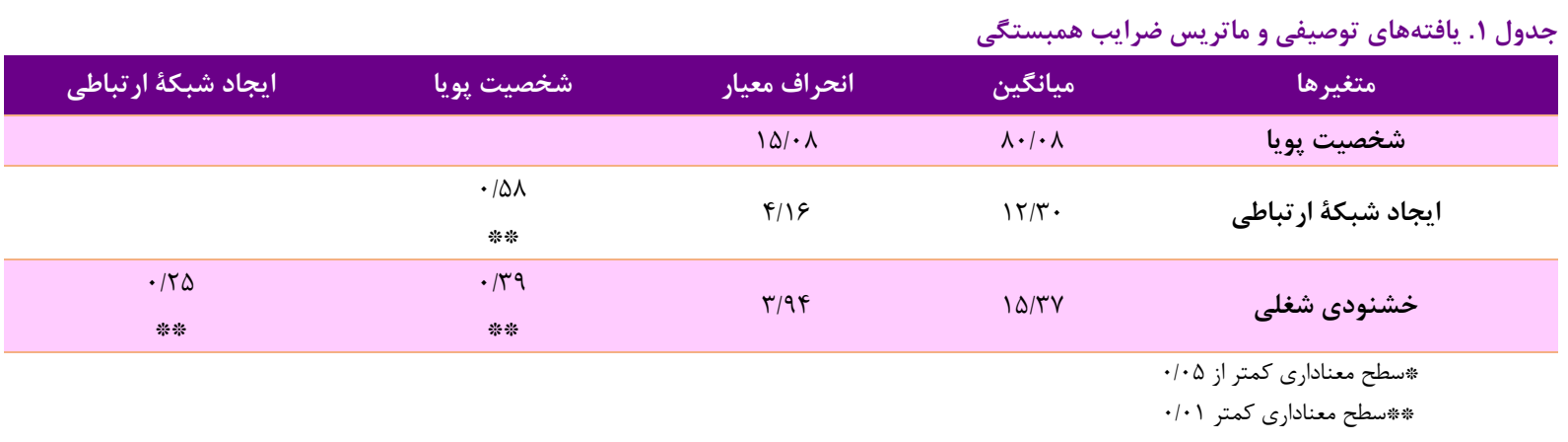

جدول r. شاخصهاى برازندَى براى الكَوى يِيشنهادى و نهايى يزووهش

\begin{tabular}{|c|c|c|c|c|c|c|c|c|}
\hline RMSEA & NFI & CFI & TLI & IFI & AGFI & GFI & $\frac{x^{2}}{d f}$ & شاخص برازندَّى الََو \\
\hline .1 .9 & .199 &.$/ 99$ &.$/ 99$ & .199 & $\cdot / 94$ &.$/ 99$ & $r / 9$. & الكَى پِيشنهادى \\
\hline$\cdot 1 \cdot \omega$ & .191 &.$/ 99$ &.$/ 99$ & .199 & .199 &.$/ 99$ & $\mid / 41$ & الخوى نهايى \\
\hline
\end{tabular}

نهايى حمايت مىكند. همانگونه كه مشاهده مىشود شاخص برازش كلى (RMSEA) در الكوى نهايى كمتر از مهئ الگوى پيشنهادى است كه هرجقدر اين شاخص كمتر باشد، نشاندهنده برازش بهتر مدل است.
همان گونه كه جدول r نشان مى دهد، الخوى ييشنهادى

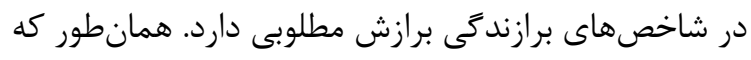

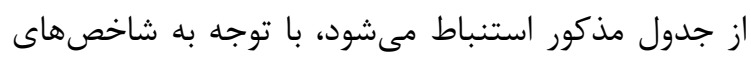

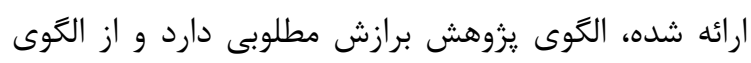


Bootstarp استفاده شد كه نتايج حاصل در جدول ץ نشان

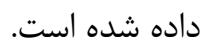

براساس مندرجات جدول بّ، مسير شخصيت يويا به ايجاد

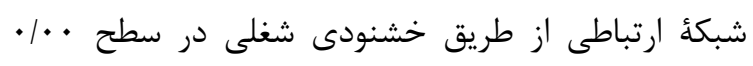

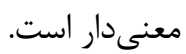

همان كونه كه در شكل r مشاهده مىشود در الكوى نهايى يزوهش ضرايب استاندارد بين متغيرهاى الكو ارائه

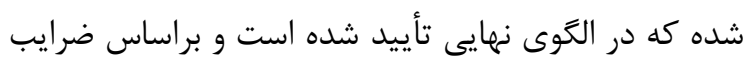
استاندارد خشنودى شغلى رابطؤ بين شخصيت يويا بائ با ايجاد

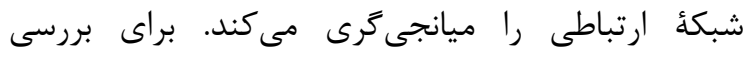

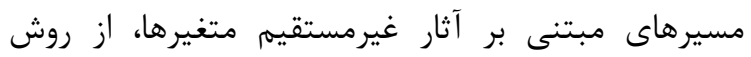

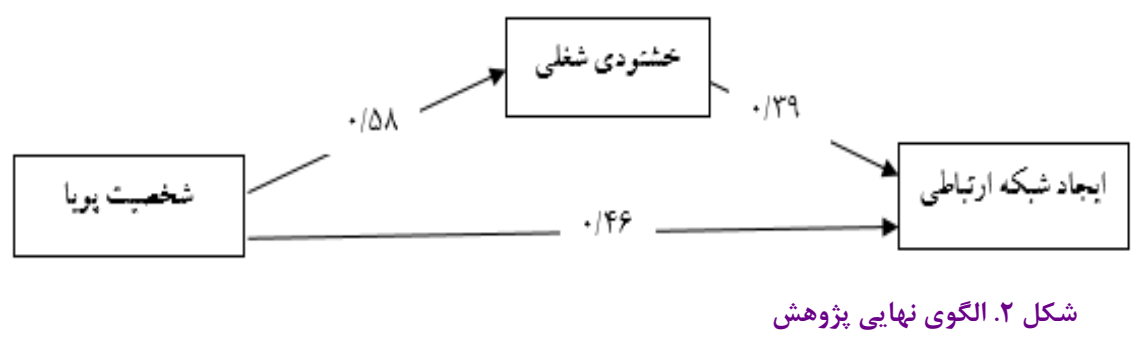

جدول شماره r. آثار غيرمستقيم متغيرها
سطح معنى دارى
حد يايين
حد بالا - 20 - n
اثر غيرمستقيم
مسيرها

$.1 \cdots$

$\cdot / 1 \Delta V$

$\cdot / 499$

$\cdot / 1 \Delta F$

ايجاد شبكؤ ارتباطى از طريق خشنودى شغلى

شوند و در محيط كارىشان ابتكار را بلهست گيرند. اين نوع

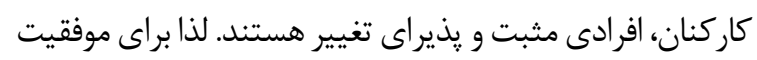

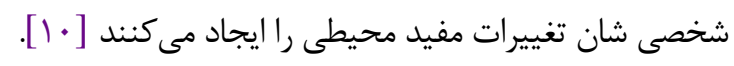

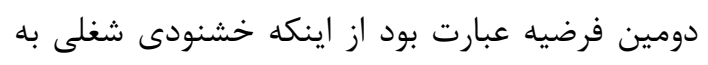
طور مستقيم بر ايجاد شبكة ارتباطى تأثير مى حذارد. نتايج

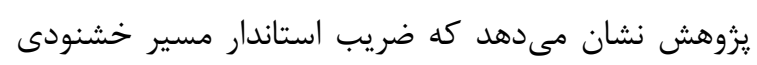

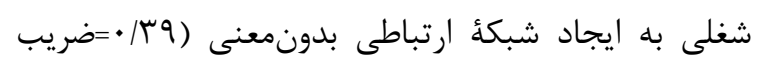
استاندار، وسب/ •="p) است. ديد عاه گرايشى (Dispositional) بيان مى كند كه خشنودى شغلى مى تواند تا اندازهاى با يك دئى

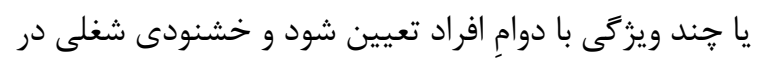

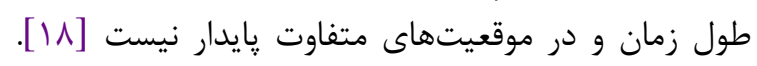
يافتههاى Herzberg مشخص مى كند كه عوامل انخيزشى،

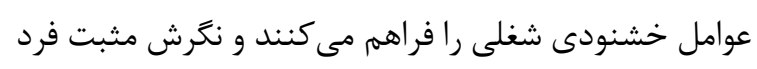

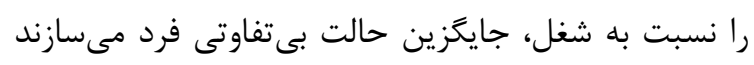
[19]. با حذف اين عوامل، در او حداقل ناخشنودى به وجود

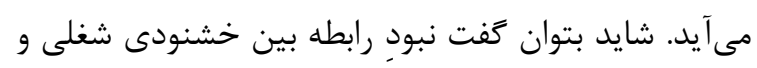

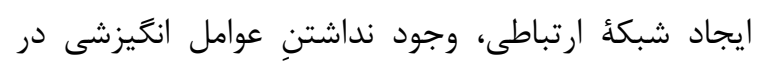
محيط كار براى اين كاركنان بوده است.

\section{بحث و نتيجه گَيرى}

هدف از انجام اين يزوهش، بررسى رابطهُ بين شخصيت

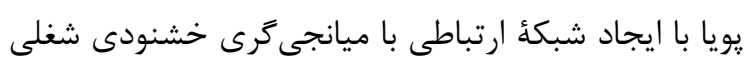
اولين فرضيهُ مطرحشده در اين يزوهش عبارت بود از اين

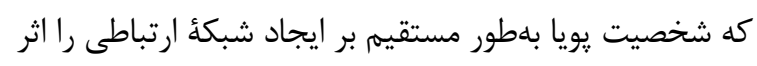

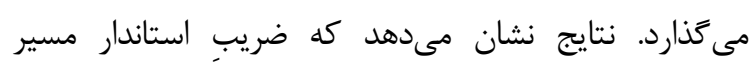
شخصيت يويا، به ايجاد شبكة ارتباطى مثبت و و معنى مدار

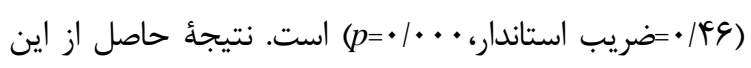

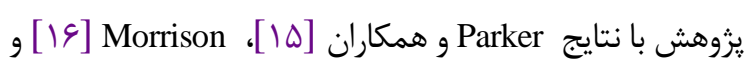

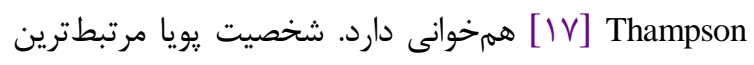

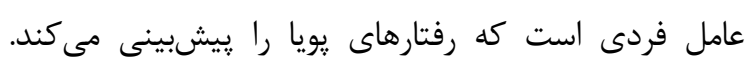

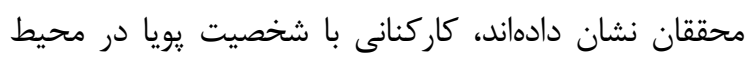

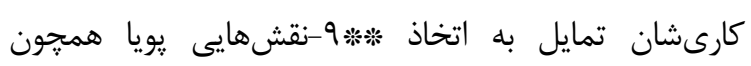
جستجوى فعالانه بازخورد، تلاش براى كاهش اطمينان با بان

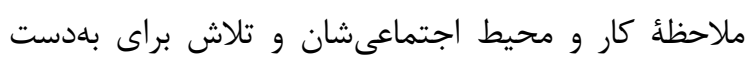
آوردن كنترل شخصى دارند [V اV، IV] كاركنان كمك مى كند تا فراتر از وظايف رسمى رفته ورن رون روابط بين شخصى مفيدى ايجاد كنند، در فرايند ييشرفت دركير 
تأثير گذار باشد و در صورت بالا بودن خشنودى شغلى، فرد

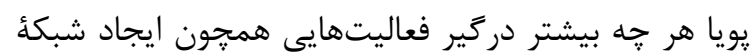
ارتباطى از طريق جستجوى اطلاعات باشد.

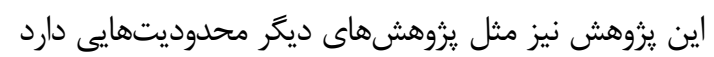

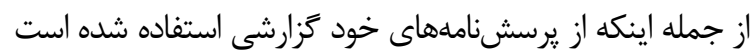
كه محدوديتهاى خاصى دارند. همجنين از آنجا كه جامعأ

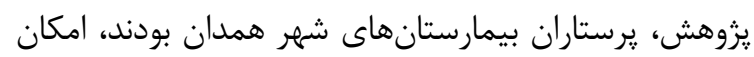

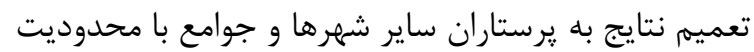

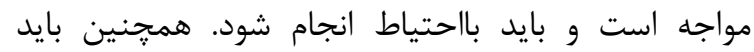

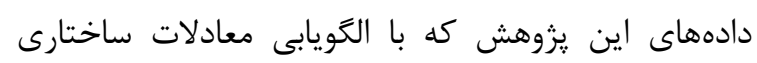

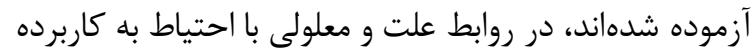

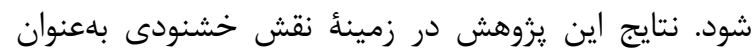

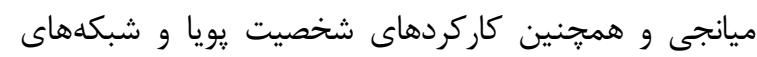

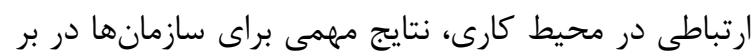

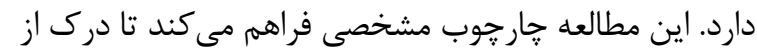

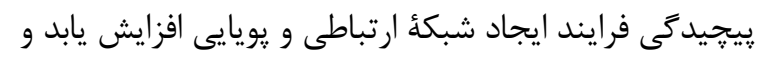
به شناسايى شيوهها و مداخلههايى كمك كند كه روند ايجاد

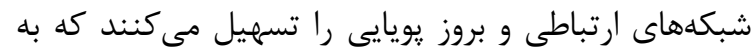

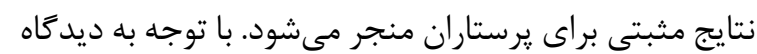

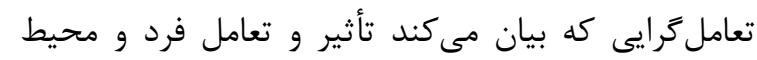

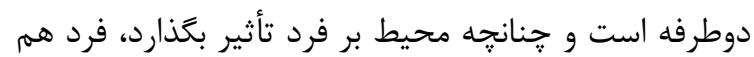

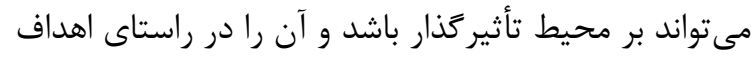

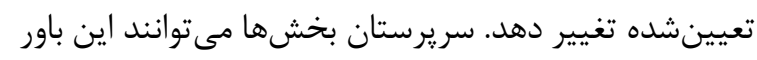

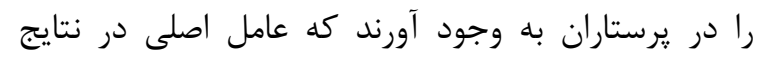
كارىشان، خود يرستاران هستند و با داشتن شخصيت يويا

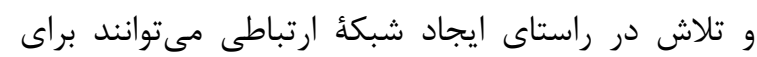

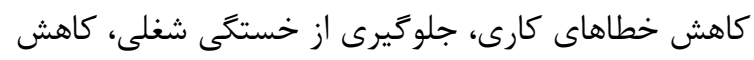

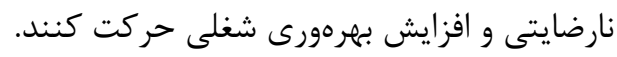

\section{تقدير و تشكر}

بدين وسيله از تمام كسانى كه ما را در انجام اين يزوهش ونش يارى كردند، تشكر و قدردانى مى كنيم.

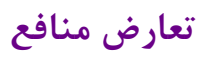

بين نويسند
فرضيأ سوم بدين كونه مطرح شده بود كه شخصيت يويا

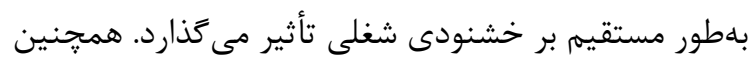

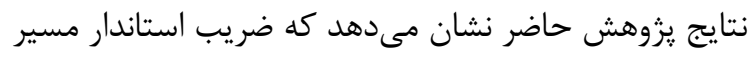

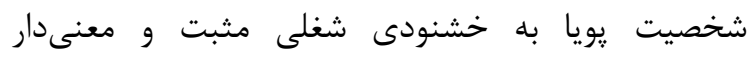

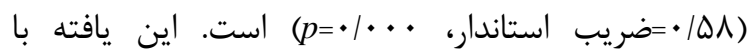

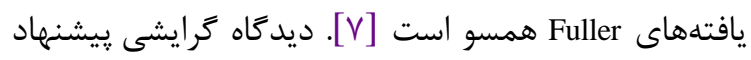

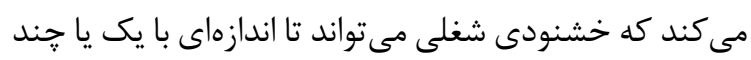
ويزگى ثابت افراد تعيين شود و در طول زمان و در دران

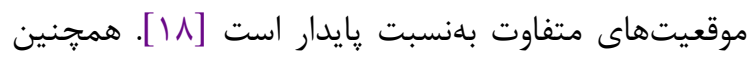
نشان داده شد كه شخصيت يويا با خشنودى شغلى بسيار مرتبط است جون افراد با شخصيت يويا تمايل دارند شرايطى ندي ايجاد كنند كه سبب موفقيت شخصى شان در كارها شود.

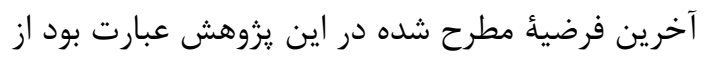
ميانجى

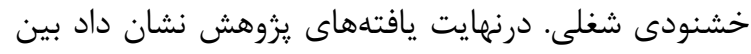

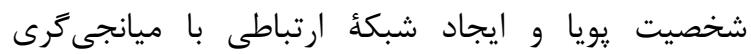
خشنودى شغلى رابطؤ مثبت غيرمستقيم وجود دارد. اين

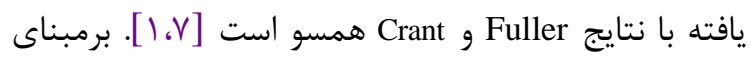
نظر Crant و Bateman مسائل موقعيتى افرادى كه شخصيت يويا دارند را كمتر تحت فشار مى كذارد و آنها تمايل بيشترى

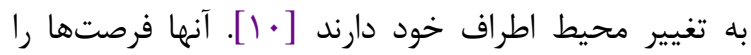

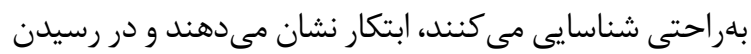

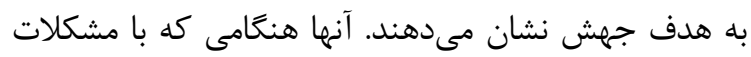

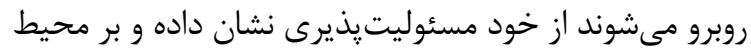
اطراف خود اثر مى كذارند. ييايند اين وضعيت آن است كه

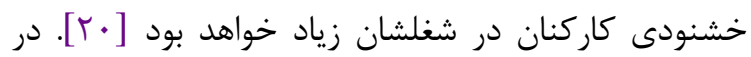

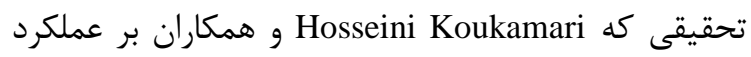
انطباقى يرستاران انجام دادند، به اين نتيجه رسيدند كه كاركنان در محيط شغلى خود از حل خلاقانئ مشكلات

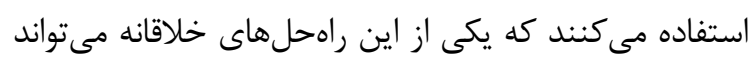

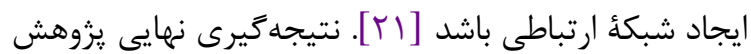

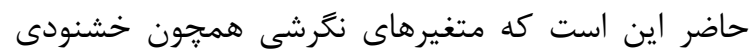

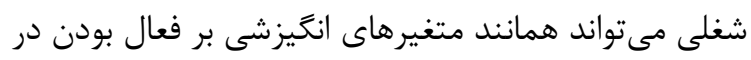

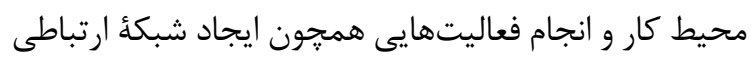




\section{References}

1. Crant JM. The proactive personality scale and objective job performance among real estate agents. J Appl Psychol. 1995;80(4):532-7. https://doi.org/10.1037/ 0021-9010.80.4.532.

2. Crant JM. Proactive behavior in organizations. J Manage. 2011;26(3):435-62. https://doi.org/10.1177/0149206 30002600304.

3. George G. Human Relations Development: A Manual for Educators. Boston: Allyn \& Bacon; 1973.34.

4. Salahian A, Oreizi H, Babamiri M, Asgari A. The predictor factors of burnout syndrome in Isfahan nurses. Iran J Nurs Res. 2012;6(23):22-31.

5. Babamiri M, Moeini B, Tahmasian H, Barati M, Roshanai G. The study of sleep health education effect on sleep quality among lorestan nursing personnel. J Econ. 2017;4(4):8-13.

6. Gong Y, Cheung S, Wang M, Huang J. Unfolding the proactive process for creativity: integration of the employee proactivity, information exchange, and psychological safety perspectives. J Manage. 2012;38(5):1611-33. https://doi.org/10.1177/01492 $\underline{06310380250 .}$.

7. Fuller B Jr, Marler LE. Change driven by nature: A metaanalytic review of the proactive personality literature. $\mathrm{J}$ Vocat Behav. 2009;75(3):329-45. https://doi.org/10. 1016/j.jvb.2009.05.008.

8. Wanberg CR, Kammeyer-Mueller JD. Predictors and outcomes of proactivity in the socialization process. $\mathrm{J}$ Appl Psychol. 2000 Jun;85(3):373-85. https://doi.org/ $\underline{\text { 10.1037/0021-9010.85.3.373 PMID:10900812 }}$

9. Buss DM. Selection, evocation, and manipulation. J Pers Soc Psychol. 1987;53(6):1214-21. https://doi.org/ $\underline{\text { 10.1037/0022-3514.53.6.1214 PMID:3320336 }}$

10. Bateman TS, Crant JM. The proactive component of organizational behavior: A measure and correlates. J Organ Behav. 1993;14(2):103-18. https://doi.org /10.1002/job.4030140202.

11. Zareieshamsabadi F, Noori A, Molav H. The relationship of Proactive personalities with Entrepreneurship Intentions and Career Success in the Personnel of Isfahan University of Medical Scinces. Health Inf Manag. 2014;7(2):215.
12. Ashford SJ, Black JS. Proactivity during organizational entry: the role of desire for control. J Appl Psychol. 1996;81(2):199-214. https://doi.org/10.1037/00219010.81.2.199.

13. Brayfield AH, Rothe HF. An index of job satisfaction. J Appl Psychol. 1951;35(5):307-11. https://doi.org/ 10.1037/h0055617.

14. Judge TA, Erez A, Bono JE, Thoresen CJ. The Core SelfEvaluations Sale: development of a measure. Person Psychol. 2013;56(2):303-31. htps://doi.org/ 10.1111/j.1744-6570.2003.tb00152.x.

15. Parker SK, Williams HM, Turner N. Modeling the antecedents o proactive behavior at work. J Appl Psychol. 2006;91(3):636-52. https://doi.org/10.103 7/0021-9010.91.3.636 PMID:16737360

16. Morrison EW. Longitudinal study of the effects of information seeking on newcomer socialization. J Appl Psychol. 1993;78(2):173-83. https://doi.org/10.1037 /0021-9010.78.2.173.

17. Thompson JA. Proactive personality and job performance: a social capital perspective. J Appl Psychol. 2005;90(5):1011-7. https://doi.org/10. 1037/0021-9010.90.5.1011 PMID:16162073

18. Staw BM, Boettger RD. Task revision: A neglected form of work performance. Acad Manage J. 1986;33(3):53459. https://doi.org/10.2307/256580.

19. Herzberg F. Motivation-hygiene profiles: Pinpointing what ails the organization. Organizational dynamics. 1974;3(2):18-29. https://doi.org/10.1016/00902616(74)90007-2

20. Helmreich RL, Sawin LL, Carsrud AL. The honeymoon effect in job performance: temporal increases in the predictive power of achievement motivation. J Appl Psychol. 1986;71(2):185-8. https://doi.org/10.1037/ 0021-9010.71.2.185 PMID:11538825

21. Hosseini Koukamari P, Naami A, Allahyari T. Confirmatory and exploratory factor analyses of adaptive performance scale: a study among hospital nurses. J Econ. 2015;3(1):41-9. 